\title{
Otosclerosis: Contribution of Computed Tomography and Radio-Anatomical Correlations
}

\author{
Khaled Khamassi', Madiha Mahfoudhi ${ }^{2}$, Hejer Mbarek ${ }^{1}$, Farah Hedhili' ${ }^{1}$, Ayoub Ben Yahia ${ }^{1}$, \\ Lobna Bougacha', Jihen Ben Hafdhallah' ${ }^{3}$, Najla Mnif ${ }^{3}$, Rim Lahiani', Mamia Ben Salah' \\ ${ }^{1}$ Department of Otorhinolaryngology-Head and Neck Surgery, Charles Nicolle Hospital, Tunis, Tunisia \\ ${ }^{2}$ Department of Internal Medicine A, Charles Nicolle Hospital, Tunis, Tunisia \\ ${ }^{3}$ Department of Radiology, Charles Nicolle Hospital, Tunis, Tunisia \\ Email: ${ }^{*}$ madiha mahfoudhi@yahoo.fr
}

Received 14 April 2015; accepted 7 June 2015; published 10 June 2015

Copyright (C) 2015 by authors and Scientific Research Publishing Inc.

This work is licensed under the Creative Commons Attribution International License (CC BY). http://creativecommons.org/licenses/by/4.0/

cc) (i) Open Access

\section{Abstract}

Otosclerosis is an osteodystrophia of the otic capsule, responsible for hearing loss by blocking of the stapes footplate. The purpose of this study was to evaluate the reliability of computed tomography (CT) in the positive diagnosis of otosclerosis, to compare the radiological findings to those intraoperatively, and to seek a correlation between imaging data and postoperative audiometric results. This is a retrospective study of 60 patients having otosclerosis, treated in our department between 2009 and 2011. All patients underwent an otoscopic examination, pure tone and vocal audiometry, impedancemetry and petrous CT scan. At petrous CT scan, a footplate thickening was found in 9 cases. Labyrinthine bone hypodensity was noted in $\mathbf{5 1}$ cases. Sensitivity of CT in the diagnosis of otosclerosis was $100 \%$. Regarding the operative findings and their correlation with imaging, we found that among the 7 facial canal procidences reported intraoperatively, CT had identified 6, with a sensitivity of $86 \%$. Of the 53 facial nerve in normal position intraoperatively, CT had only identified 34, with a specificity of 64\%. Regarding the ossicles, there were 6 cases of abnormalities of the incus, among them 3 were identified on CT, with a sensitivity of $50 \%$. The 54 patients with normal ossicular chain intraoperatively were all identified as such on CT, with a specificity of $100 \%(p=0.001)$. For correlation between imaging and postoperative results, it was found that patients with extended otosclerosis had lower postoperative audiometric improvement than those having localized disease $(p<0.05)$. Computed tomography is necessary for the diagnosis of otosclerosis. It also helps, with good sensitivity and specificity, seeking for anatomical variants that the surgeon could possibly encounter during surgical procedure. Finally, there is a statistically significant correlation between imaging data and postoperative audiometric results, allowing establishing a functional prognosis even before surgery.

${ }^{*}$ Corresponding author.

How to cite this paper: Khamassi, K., Mahfoudhi, M., Mbarek, H., Hedhili, F., Yahia, A.B., Bougacha, L., Hafdhallah, J.B., Mnif, N., Lahiani, R. and Salah, M.B. (2015) Otosclerosis: Contribution of Computed Tomography and Radio-Anatomical Correlations. Open Journal of Clinical Diagnostics, 5, 74-80. http://dx.doi.org/10.4236/ojcd.2015.52014 


\section{Keywords}

\section{Otosclerosis, Computed Tomography, Hearing Loss, Audiometry}

\section{Introduction}

Otosclerosis is an osterodystrophy of the otic capsule, which results in conductive and/or sensorineural hearing loss. The pathophysiology of otosclerosis is complex. The main lesions are multifocal areas of sclerosis within the endochondral temporal bone. It is linked to enzyme disorders, involving lysosomal proteolytic enzymes associated with calcium integration disorders. Its frequency is difficult to assess. Indeed, not all otoscleroses have clinical manifestations, and histological form is 10 times more common than the clinical form. The disease can be considered to be hereditary, but its penetrance and the degree of expression are so highly variable that it may be difficult to detect an inheritance pattern. Diagnosis is suspected on clinical and audiometric data. Literature review shows that petrous computed tomography (CT) is very important to make diagnosis of otoclerosis [1]. It allows the surgeon to prepare for certain difficulties he might encounter intraoperatively. It can also predict the prognosis after surgery.

The purpose of this study is to evaluate the reliability of CT in the diagnosis of otosclerosis, to compare the radiological findings to intraoperative ones, and to seek a correlation between imaging data and post-operative audiometric results.

\section{Materials and Methods}

This is a retrospective study of 60 patients having otosclerosis, treated in our department between 2009 and 2011. All patients underwent an otoscopic examination, pure tone and vocal audiometry, impedancemetry and petrous CT scan. This was done without iodine contrast media injection, in axial and coronal sections, and in oblique reconstructions in the stapes plane and in the cochlear window (to explore the "ossicular V"). All patients were operated under general anesthesia. They underwent stapedectomy and piston transposition. Postoperative tone audiometry was performed for all of them.

For this study, we were interested only in the operated side in order to compare the imaging data to the peroperative anatomical data and to the postoperative audiometric results. Imaging data included footplate thickness, perilabyrinthic hypodensity, facial canal procidence, ossicles abnormalities and narrowness of oval window. Peroperative anatomical data included the last three ones. Postoperative audiometric results were based on the comparison between pre and postoperative pure tone audiometry. Statistical analysis was performed using chi ${ }^{2}$ test.

\section{Results}

Sixty patients having otosclerosis, who were treated in our department between 2009 and 2011 were enrolled in this research. Mean age was 41 years (16 - 65 years) and sex-ratio 0.42 . Family history of hearing loss was observed in 10 patients (16.7\%), including 3 operated on for otosclerosis. All patients consulted for hearing loss. It was bilateral in 51 cases. Tinnitus was associated in 53 cases. Five patients had associated vertigo. Otoscopy showed complete normal tympanic membrane in all cases (Table 1).

Among the 60 operated ears, pure tone audiometry showed conductive hearing loss in 45 cases (75\%) and mixed hearing loss in 15 cases (25\%). Air-bone gap varied between 30 and 70 decibels (dB). Tympanogram was central with decreased compliance, and acoustic reflex was absent in all cases. Vocal audiometry showed intelligibility threshold range between 40 and $90 \mathrm{~dB}$. Maximal intelligibility rate ranged from $60 \%$ to $100 \%$.

At petrous CT scan, a hypodense footplate having a thickness of more than $0.6 \mathrm{~mm}$ was considered as thick and was found in 9 cases (Figure 1). Perilabyrinthic hypodensity was found in 51 cases (Figure 2). Distribution of our patients according to Veillon classification is summarized in Table 2. All patients had CT suggestive of otosclerosis. The sensitivity of CT in the positive diagnosis was thus $100 \%$. We found no relationship between the degree of extension of otosclerotic lesions and the average age of our patients $(p=0.08)$. Similarly, there is no statistically significant correlation between the degree of extension on CT and the presence of a family history 
Table 1. Socio-demographic and clinical data.

\begin{tabular}{cc} 
Mean age & 41 years \\
Sex-ratio & 0.42 \\
Family history of hearing loss & 10 cases \\
Clinical symptoms: & \\
-hearing loss & 60 cases \\
-tinnitus & 53 cases \\
-vertigo & 5 cases \\
\hline
\end{tabular}

Table 2. Percentage of patients according to Veillon classification.

\begin{tabular}{ccc}
\hline Radiological type & Number of cases & Percentage (\%) \\
\hline I a & 9 & 15 \\
I b & 0 & 0 \\
II & 39 & 65 \\
III & 9 & 15 \\
IV a & 2 & 3 \\
IV b & 1 & 2 \\
Total & 60 & 100 \\
\hline
\end{tabular}

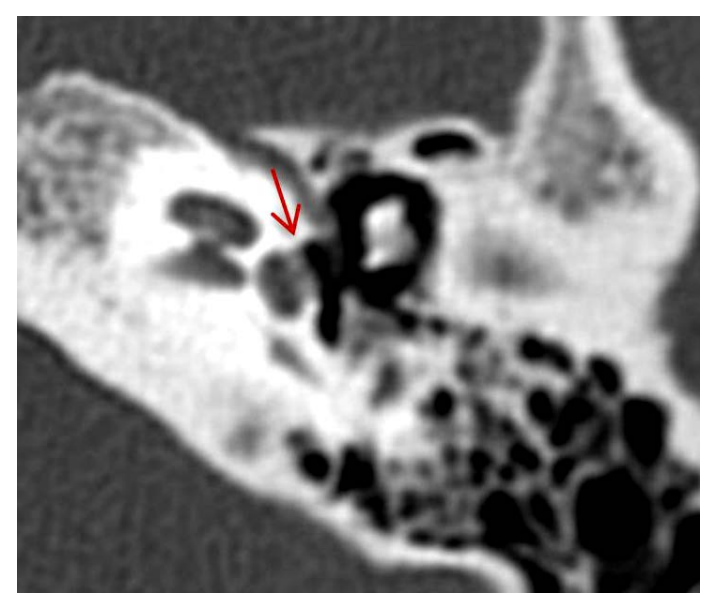

Figure 1. (Axial CT, left petrous bone): Footplate thickening.

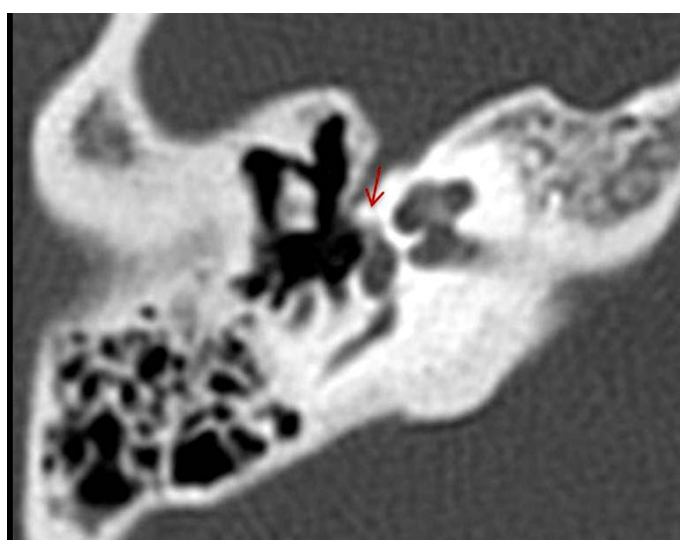

Figure 2. (Axial CT, right petrous bone): Perilabyrinthic hypodensity. 
of hearing loss $(\mathrm{p}=0.30)$.

Regarding to operative findings and their correlation with imaging, we found that among the 7 cases of facial canal procidences reported intraoperatively, CT had identified 6 (Figure 3), with a sensitivity of $86 \%$. Of the 53 facial nerves in normal position intraoperatively, CT identified as 34 , with a specificity of $64 \%$. Thus, CT identified one false negative and 19 false positives. CT presents a statistically significant diagnostic value $(p=0.017)$ on the facial nerve canal prolapse in terms of sensitivity, but a lower level of specificity.

Concerning the ossicles, there were 6 cases of abnormalities of the long process of the incus observed intraoperatively, 3 were identified on CT (Figure 4), with a sensitivity of 50\% (not statistically significant). The 54 patients with normal ossicular chain intraoperatively were all identified as such on CT, with a specificity of $100 \%$ $(p=0.001)$. Furthermore, we found 16 narrow oval windows intraoperatively, 12 of which were identified on CT, with a sensitivity of $75 \%$.

The prognostic approach was to find a correlation between imaging and postoperative audiometric results. To do this, we divided the patients into two groups: localized otosclerosis group (grouping stages I and II of Veillon classification, 48 cases) and extended otosclerosis group (stages III and IV, 12 cases). This classification has a direct impact on preoperative tonal audiometry. Indeed, the thresholds of preoperative pure tone audiometry were significantly higher in cases of extended otosclerosis. We then calculated the average of air conduction, the average of bone conduction and the average of pre and postoperative air-bon gap. These results are shown in Table 3. Patients classified stage III or IV had lower postoperative audiometric improvement than the group

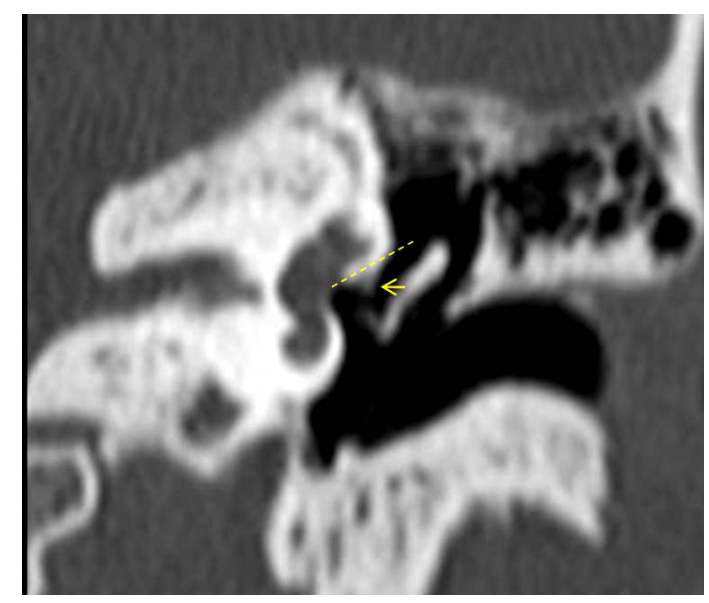

Figure 3. (Coronal CT, left petrous bone): Facial canal prolapse.

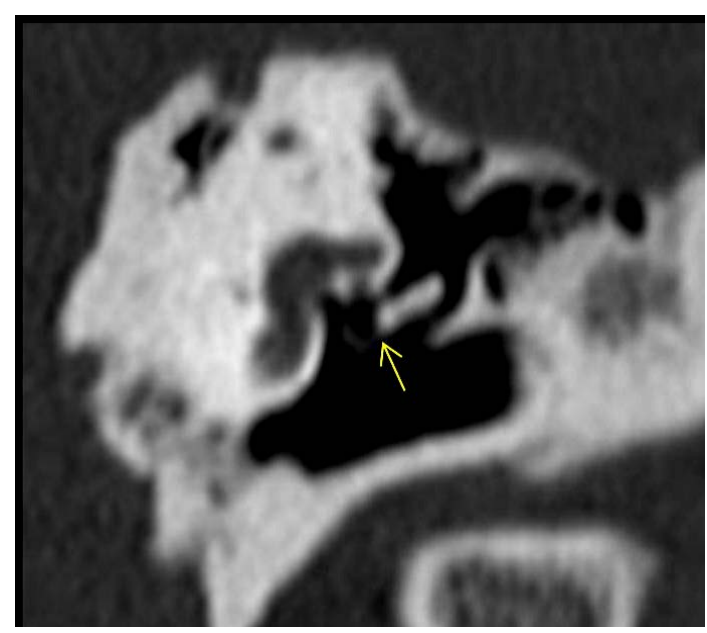

Figure 4. (Coronal CT, left petrous bone): Partial lysis of the incus long process. 
Table 3. Average (in decibels) of air and bone conductions and of air-bone gaps according to otosclerosis extension.

\begin{tabular}{ccccccc}
\hline & $\begin{array}{c}\text { Preoperative } \\
\text { air conduction }\end{array}$ & $\begin{array}{c}\text { Postoperative } \\
\text { air conduction }\end{array}$ & $\begin{array}{c}\text { Preoperative } \\
\text { bone } \\
\text { conduction }\end{array}$ & $\begin{array}{c}\text { Postoperative } \\
\text { bone } \\
\text { conduction }\end{array}$ & $\begin{array}{c}\text { Preoperative } \\
\text { air-bone gap }\end{array}$ & $\begin{array}{c}\text { Postoperative } \\
\text { air-bone gap }\end{array}$ \\
\hline $\begin{array}{c}\text { Localized } \\
\text { otosclerosis }\end{array}$ & 55 & 20 & 10 & 10 & 45 & 10 \\
$\begin{array}{c}\text { Extended } \\
\text { otosclerosis }\end{array}$ & 70 & 40 & 35 & 35 & 35 & 15 \\
& & & & & $\mathrm{p}<0.05$ & $\mathrm{p}<0.05$ \\
\hline
\end{tabular}

classified stage I and II $(\mathrm{p}<0.05)$. Thus, the results of the postoperative tone audiometry are statistically correlated with the otosclerotic lesions degree of extension on CT.

\section{Discussion}

Otosclerosis manifests clinically only when histological foci reached a sufficient size, thus fixing the footplate [2]. Unilateral or bilateral progressive hearing loss is the main symptom (all the cases of our series). Tinnitus is frequently associated (88.3\% in our series). Dizziness is rare (8.3\% in our series). Otoscopy shows a normal tympanic membrane. Pure tone audiometry shows conductive or mixed hearing loss ( $75 \%$ and $25 \%$ respectively in our series). A notch on the bone conduction at the 1000 or $2000 \mathrm{~Hz}$ frequency (called Carhart notch) may be found in some cases. Impedancemetry shows a peak tympanometry centered on zero with normal or decreased amplitude, associated with the absence of acoustic reflex [2] [3].

Petrous computed tomography should look for two basic radiological signs in otosclerosis, namely the footplate thickening and the presence of perilabyrinthic hypodensities. Normal footplate is about $0.5 \mathrm{~mm}$ thick. A greater than $0.6 \mathrm{~mm}$ thickening is considered one of the main criteria for diagnosis [4] [5]. For hypodensities, it is the radiological translation of the active otosclerotic foci. These demineralization foci are found in 4 predilection sites which are:

- The fissula antefenestram (anterior to the footplate): We found it in $65 \%$ of cases in our series. It is the predilection site of otosclerosis [6] [7]. It is an embryonic fibrocartilaginous remaining located on the anterior edge of the oval window (called also vestibular window). According to Veillon, this location is found in $80.9 \%$ of the analyzed ears [4].

- The other sites include cochlear (or round) window (2.9\% to 9.5\% of cases), peri-cochlear capsule and the anterior wall of the internal auditory canal [4] [8]-[11].

In 1993, Valvassori [6] reported that the otosclerotic lesion must be greater than or equal to $1 \mathrm{~mm}$ to be visible on CT sections. Therefore, he considers that the infra-radiological forms of otosclerosis correspond to superficial foci, which are too small to be seen on CT. In retrospective studies conducted between 1996 and 1999 for the diagnosis of 437 cases of otosclerosis, CT, which section thickness was $1 \mathrm{~mm}$, had a sensitivity of $91 \%$. Lagleyre et al. [8] have found a better sensitivity: $95 \%$ for a $0.6 \mathrm{~mm}$ section thickness. Thus, the improved resolution by the use of spiral (or helical) CT and the reduction in section thickness have reduced the frequency of infra-radiological forms and improved the CT sensitivity in the diagnosis of otosclerosis. For Marx, this highresolution CT can detect different forms of otosclerosis with a sensitivity of $95 \%$ and a specificity of $99.1 \%$ [12].

It is essential that imaging can identify potential problems that may be encountered during surgery. The narrowness of the oval window $(<1.4 \mathrm{~mm})$ is the most frequent abnormality [1] [13]. In our series, it was found in $26.6 \%$ of cases (16 narrow oval window among the 60 operated ears), and the sensitivity of CT to detect that was $75 \%$. In a retrospective study of 293 ears operated for otosclerosis, Ayache found 36 cases (12.3\%) of narrow oval window intraoperatively [13].

Anatomical variations of facial canal are the second anomaly to search on CT. It can be a dehiscence by bone defect, or prolapse, defined by a low position of the facial canal at the oval window [4]. In our series, CT has identified 6 procidences of the facial canal among 7 confirmed intraoperatively, with a sensitivity of $86 \%$. According to Swartz, prolapse corresponds to the visualization of a structure having tissular density localized under the lateral semi-circular canal and projecting on the same level as the oval window in coronal section [14]. In a study of 293 ears operated for otosclerosis, abnormal facial canal (prolapse and/or dehiscence) accounted for 8.9\% 
[13].

In addition, CT can also assess the integrity of the long process of the incus, which is very important to evaluate since it is the future piston support. It allows also seeking for signs suggesting geyser ear, which represents an absolute contra-indication for stapes or footplate surgery [15]. This anomaly is related to the abnormal presence of cerebrospinal fluid in the inner ear with labyrinthic hyperpressure and geyser risk when the footplate is opened. Bone lesions that result from hyperpression can be found in many sites in the internal auditory canal and in the labyrinthine segment of the facial canal [15].

Regarding imaging and postoperative results correlations, several authors noted a statistically significant relationship between the stage of otosclerosis and the improvement of hearing thresholds postoperatively. In a study of 437 CT, Shin et al. found, in patients with extended otosclerosis, a statistically significant high postoperative air and bone conduction thresholds (and then a lower improvement), compared to the group formed by patients with localized otosclerosis [10]. Marx has shown, in a series of 200 patients operated, that the group with extensive disease or with high preoperative air and bone conduction thresholds have a reduced chance to improve these levels compared to patients with radiologically localized otosclerosis [12]. The results of our study are statistically significative and confirm these literature findings. It is therefore important to inform the patient, before any surgical procedure, about the relative effectiveness of surgery in case of an extended otosclerosis.

Furthermore, it was found in several studies that the invasion of the cochlear endoste by the otosclerotic foci on CT is correlated with a poor prognosis [4] [10] [16] [17]. Indeed, this phenomenon leads to a release of enzymes in the labyrinthine fluid, causing inflammation and degeneration of intra-cochlear structures, which can lead to severe sensorineural hearing loss [4] [18]-[20].

\section{Conclusion}

Computed tomography is necessary for the diagnosis of otosclerosis. It also helps, with good sensitivity and specificity, seeking for anatomical variants that the surgeon could possibly encounter during surgical procedure. Finally, there is a statistically significant correlation between imaging data and postoperative audiometric results, allowing establishing a functional prognosis even before surgery.

\section{Conflict of Interest}

There are no conflicts of interest.

\section{References}

[1] Ukkola-Pons, E., Ayache, D., Pons, Y., Ratajczak, M., Nioche, C. and Williams, M. (2013) Oval Window Niche Height: Quantitative Evaluation with CT before Stapes Surgery for Otosclerosis. American Journal of Neuroradiology, 34, 1082-1085. http://dx.doi.org/10.3174/ajnr.A3354

[2] Hinojosa, R. and Marion, M. (1987) Otosclerosis and Sensorineural Hearing Loss: A Histopathologic Study. American Journal of Otolaryngology, 8, 296-307. http://dx.doi.org/10.1016/S0196-0709(87)80048-0

[3] Schunecht, H.F. and Barber, W. (1985) Histologic Variants in Otosclerosis. Laryngoscope, 95, 1307-1317.

[4] Veillon, F., Stierle, J.L., Dussaix, J. and Riehm, S. (2006) Imagerie de l'otospongiose: Confrontation clinique et imagerie. Journal de Radiologie, 87, 1756-1764. http://dx.doi.org/10.1016/s0221-0363(06)74157-9

[5] Shin, Y.J., Calvas, P., Deguine, O., Charlet, J.P., Cognard, C. and Fraysse, B. (2001) Correlations between Computed Tomography Findings and Family History in Otosclerotic Patients. Otology \& Neurotology, 22, 461-464. http://dx.doi.org/10.1097/00129492-200107000-00008

[6] Valvassori, G.E. (1993) Imaging of Otosclerosis. Otolaryngologic Clinics of North America, 26, 359-371.

[7] Vignaud, J., Jardin, C. and Rosen, L. (2003) The Ear Diagnosis Imaging: CT Scanner, Tomography and Magnetic Resonance. The Annals of Otology, Rhinology, and Laryngology, 112, 348-355.

[8] Lagleyre, S., Sorrentino, T., Calmels, M.N., Shin, Y.J., Escudé, B., Deguine, O., et al. (2009) Reliability of HighResolution CT Scan in Diagnosis of Otosclerosis. Otology \& Neurotology, 30, 1152-1159. http://dx.doi.org/10.1097/MAO.0b013e3181c2a084

[9] Naumann, I.C., Porcellini, B. and Fisch U. (2005) Otosclerosis: Incidence of Positive Findings on High Resolution Computed Tomography and Their Correlation to Audiological Test Data. Annals of Otology, Rhinology \& Laryngology, 114, 709-716. http://dx.doi.org/10.1177/000348940511400910 
[10] Shin, Y.J., Fraysse, B., Deguine, O., Cognard, C., Charlet, J.P. and Sévely, A. (2001) Sensorineural Hearing Loss and Otosclerosis: A Clinical and Radiologic Survey of 437 Cases. Acta Oto-laryngologica, 121, 200-204. http://dx.doi.org/10.1080/000164801300043505

[11] Vicente Ade, O., Yamashita, H.K., Albernaz, P.L. and Penidonde, O. (2006) Computed Tomography in the Diagnostic of Otosclerosis. Otolaryngology—Head and Neck Surgery, 134, 685-692. http://dx.doi.org/10.1016/j.otohns.2005.11.030

[12] Marx, M., Lagleyre, S., Escude, B., Demeslay, J., Elhadi, T., Deguine, O., et al. (2011) Correlations between CT Scan Findings and Hearing Thresholds in Otosclerosis. Acta Oto-laryngologica, 131, 351-357. http://dx.doi.org/10.3109/00016489.2010.549841

[13] Ayache, D., Sleiman, J., Nengsu, A. and Elbaz, P. (1999) Variantes et incidents per-opératoires observés au cours de la chirurgie de l'otospongiose. Annales d'oto-laryngologie et de chirurgie cervico-faciale, 116, 8-14.

[14] Swartz, J.D. (1984) The Facial Nerve Canal. CT Analysis of the Protruding Tympanic Segment. Radiology, 153, 443447. http://dx.doi.org/10.1148/radiology.153.2.6484176

[15] Couvreur, P.H., Baltazart, B., Lacher, G., Filippini, J.P. and Vincey, P. (2003) Geyser lors de la chirurgie de l'otospongiose. Revue de laryngologie, d'otologie et de rhinologie, 124, 31-37.

[16] Bonafé, A. (1999) Imagerie des surdités de transmission. Journal de Radiologie, 80, 1772-1779.

[17] Mansour, S., Nicolas, K. and Hassen, H.A. (2011) Round Window Otosclerosis: Radiologic Classification and Clinical Correlations. Otology and Neurootology, 32, 384-392. http://dx.doi.org/10.1097/MAO.0b013e3182096e80

[18] Hayashi, H., Onerci, O. and Paparella, M.M. (2006) Cochlear Otosclerosis. Otology \& Neurotology, 27, 905-906. http://dx.doi.org/10.1097/01.mao.0000227901.65409.b1

[19] Kiyomizu, K., Tono, T., Yang, D., Haruta, A., Kodama, T. and Komune, S. (2004) Correlation of CT Analysis and Audiometry in Japanese Otosclerosis. Auris Nasus Larynx, 31, 125-129. http://dx.doi.org/10.1016/j.anl.2004.01.006

[20] Redfors, Y.D., Gröndahl, H.G., Hellgren, J., Lindfors, N., Nilsson, I. and Möller, C. (2012) Otosclerosis: Anatomy and Pathology in the Temporal Bone Assessed by Multi-Slice and Cone-Beam CT. Otology and Neurootology, 33, 922-927. http://dx.doi.org/10.1097/mao.0b013e318259b38c 